\title{
Usefulness of 0.5\% Hyperbaric Bupivacaine with Dexmedetomidine on Spinal Anaesthesia in Lower Limb Orthopaedic Patients
}

\author{
N R Arjun ${ }^{\circledast 1}$, Nischala Reddy G ${ }^{2}$, K. Narayana Prasad ${ }^{\circledR 3}$, Uthkala B Hegde $\odot 4$ \\ ${ }^{1}$ Assistant Professor, Department of Critical Care Medicine, Kasturba Medical College and Hospital, Manipal, Karnataka, India, ${ }^{2}$ Registrar, Department of Anesthesia, \\ Virinchi Hospital, Hyderabad, Telangana, India, ${ }^{3}$ Assistant Professor, Department of Anaesthesia, NIMRA Institute of Medical Sciences, Jupudi, Ibrahimpatnm, \\ Vijayawada, Andhra Pradesh, India, ${ }^{4}$ Professor, Department of Anaesthesiology, MVJ Medical College and Research Hospital, Hoskote, Banglore, India.
}

\section{Abstract}

Background: The present study was conducted to assess the usefulness of $0.5 \%$ hyperbaric bupivacaine with dexmedetomidine on spinal anesthesia in lower limb orthopedic patients. Subjects and Methods: This study involved 50 patients with ASA Grade I and II of both genders. Patients were randomly allocated into group I ( $\mathrm{n}=25$ ) Patients received Dexmedetomidine $0.5 \mu \mathrm{g} / \mathrm{kg}$ over 15 minutes using an infusion pump 20 minutes prior to $\mathrm{SAB}$ and group II $(\mathrm{n}=25)$ Intraoperatively HR, BP and SpO2 were measured and noted. Results: The mean heart rate at baseline was $80.00 \pm 8.49$ in group I and $81.80 \pm 8.74$ in group II. The mean heart rate at 5 minutes was $73.80 \pm 13.38$ in group I which was significantly higher ( $\mathrm{p}=0.02$ ) compared to $65.63 \pm 12.45$ in group II. The mean arterial pressure at baseline was $97.64 \pm 5.24$ in group I and $97.73 \pm 6.96$ in group II suggesting MAP in both groups was comparable. The MAP at 5 minutes was $90.73 \pm 14.65$ in group I which was significantly higher ( $\mathrm{p}=0.01$ ) compared to $81.22 \pm 11.64$ in group II, suggesting a greater fall from the baseline in group II compared to group I. The MAP in both groups was found to be comparable at $15,30,45,60,75,90,105,120$ minutes ( $>0.05)$. The oxygen saturation in both groups was found to be comparable at all time intervals. The duration of onset of sensory blockade (Time is taken to reach T10 level) in $53.33 \%$ of patients in Group I is between 1 to 2 minutes (60 to 120 seconds) and less than 1 minute ( 60 seconds) in $46.67 \%$ of patients. The average mean time and standard deviation of onset of sensory blockade in Group I is $66 \pm 44.14$ seconds. Conclusion: Authors found that dexmedetomidine was given intravenously as premedication before spinal anaesthesia using injection bupivacaine results in a quicker onset of analgesia, prolonged duration of sensory, motor block and well balanced hemodynamic parameters.

Keywords: Dexmedetomidine, Sensory, Motor block

Corresponding Author: K. Narayana Prasad, Assistant Professor, Department of Anaesthesia, NIMRA Institute of Medical Sciences, Jupudi, Ibrahimpatnm, Vijayawada, Andhra Pradesh, India.

E-mail: kondreddi@yahoo.com

Received: 04 July 2020

Revised: 19 August 2020

Accepted: 27 August 2020

Published: 16 December 2020

\section{Introduction}

Trauma is a major cause of mortality throughout the world. In addition to the cost in lives, productivity, and money, trauma exacts a steep toll on patients in the form of physical suffering and mental anguish. ${ }^{[1]}$ In recent years, major advances have been made in the management of trauma, the end result of which has reduced mortality and enhanced function. One of these areas is pain control. Improved pain management for blunt trauma to the lower extremity has not only led to increased comfort in trauma patients but has also been shown to reduce morbidity, early ambulation and improve long-term outcomes. ${ }^{[2]}$

The polypharmacological approach is the most common practice to treat perioperative pain, as no single agent has yet been identified to specifically inhibit nociception without associated side effects. Different techniques and drugs had been studied in order to prolong the duration of regional anesthesia and achieve postoperative pain relief. Opioids are commonly added to local anesthetics to produce spinal and epidural anesthesia. ${ }^{[3]}$ However, significant adverse effects such as urinary retention, respiratory depression, hemodynamic instability, pruritus and occasionally severe nausea and vomiting, may limit their use. ${ }^{[4]}$

Dexmedetomidine, a highly selective $\alpha 2$ agonist is rapidly emerging as the choice of additive to spinal anesthesia in view of its property to provide analgesia and awake sedation without respiratory depression along with stable hemodynamics. ${ }^{[5]}$ Various studies conducted by different authors have used dexmedetomidine in doses of $3 \mu \mathrm{g}, 5$ 
$\mu \mathrm{g}, 10 \mu \mathrm{g}$ and $15 \mu \mathrm{g}$ and there may be a dose-related prolongation of the duration of the motor blockade along with an increase in the incidence of side effects of dexmedetomidine namely hypotension and bradycardia. ${ }^{[6]}$ Hence, there seems to be no clear consensus on the dose of dexmedetomidine to be used as an additive to hyperbaric bupivacaine in spinal anaesthesia for daily practice. ${ }^{[7]}$ The present study was conducted to assess the usefulness of $0.5 \%$ hyperbaric bupivacaine with dexmedetomidine on spinal anaesthesia in lower limb orthopaedic patients.

\section{Subjects and Methods}

This study involved 50 patients with ASA Grade I and II of both genders. Patients were randomly allocated into group I ( $\mathrm{n}=25)$ Patients received Dexmedetomidine $0.5 \mu \mathrm{g} / \mathrm{kg}$ over 15 minutes using infusion pump 20 minutes prior to $\mathrm{SAB}$ and group II ( $\mathrm{n}=25)$ Patients received $0.1 \mathrm{~mL} / \mathrm{kg}$ normal saline over 15 minutes using infusion pump 20 minutes prior to SAB.

Baseline hemodynamic parameters were noted, Intraoperatively $\mathrm{HR}, \mathrm{BP}$ and $\mathrm{SpO} 2$ were measured and noted. The vitals were monitored every 15 minutes until the end of the surgery. Results were tabulated and subjected to statistics. A P-value of less than 0.05 was considered significant.

\section{Results}

[Table 1] shows that the mean heart rate at baseline was $80.00 \pm 8.49$ in group I and $81.80 \pm 8.74$ in group II. The mean heart rate at 5 minutes was $73.80 \pm 13.38$ in group I which was significantly higher $(\mathrm{p}=0.02)$ compared to $65.63 \pm$ 12.45 in group II. Similarly, the mean heart rate at 15 minutes was $68.63 \pm 10.30$ in group I which was significantly higher $(\mathrm{p}=0.04)$ compared to $63.47 \pm 8.70$ in group II, suggesting a steeper fall from the baseline in group II compared to a gradual fall in group I. The heart rate in both groups was found to be comparable at $30,45,60,75,90$ minutes $(\mathrm{p}>0.05)$.

[Table 2] shows that the mean arterial pressure at baseline was $97.64 \pm 5.24$ in group I and $97.73 \pm 6.96$ in group II suggesting MAP in both groups was comparable. The MAP at 5 minutes was $90.73 \pm 14.65$ in group I which was significantly higher $(\mathrm{p}=0.01)$ compared to $81.22 \pm 11.64$ in group II, suggesting a greater fall from the baseline in group II compared to group I. The MAP in both groups was found to be comparable at $15,30,45,60,75,90,105,120$ minutes ( $\mathrm{p}>0.05$ ). The MAP in both groups reached the lowest value at approximately the same time that is around 30 minutes. The MAP at 135 minutes, 165 minutes and 180 minutes in group I ( $87.51 \pm 5.58$, and $92.78 \pm 6.75$ and $94.02 \pm 7.19$ respectively) was significantly lower ( $\mathrm{p}=0.01, \mathrm{p}=0.05$ and $\mathrm{p}=0.04$ respectively) than group II $(91.91 \pm 7.11,96.22 \pm 6.49$, and $97.56 \pm 5.42$ respectively) suggesting a steeper rise in MAP in group II. Both the fall and the subsequent rise in mean heart rate in group I was more gradual as compared to the steep fall and rise in group II, as seen in the graph.

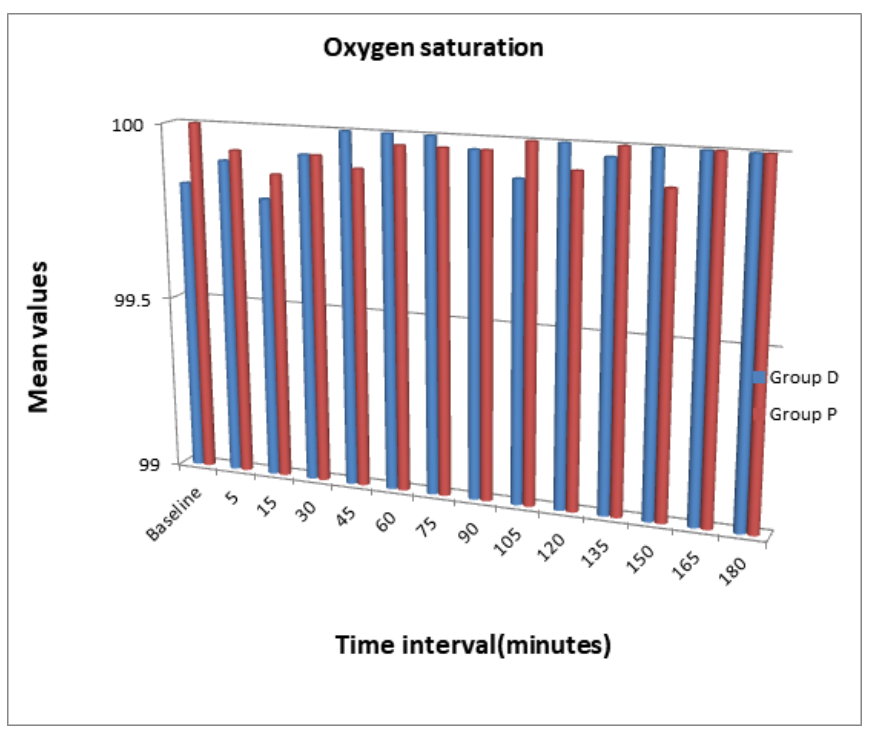

Figure 1: Assessment of oxygen saturation

[Figure 1] shows that the oxygen saturation in both the groups was found to be comparable at all time intervals.

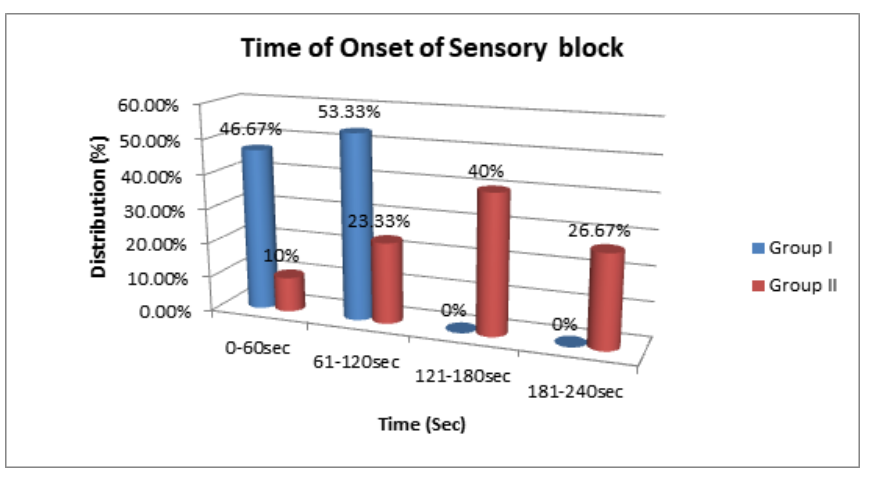

Figure 2: Onset of sensory block

[Figure 2] shows that the duration of onset of sensory blockade (Time is taken to reach T10 level) in $53.33 \%$ of patients in Group I is between 1 to 2 minutes (60 to 120 seconds) and less than 1 minute ( 60 seconds) in $46.67 \%$ of patients. The average mean time and standard deviation of onset of sensory blockade in Group I is $66 \pm 44.14$ seconds. The duration of onset of sensory block in $40 \%$ of the patients in Group II is between 2 to 3 minutes (120 to 180 seconds), and 3 to 4 minutes in $26.67 \%$ of patients and 1 to 2 minutes (60 to 120 seconds) in $23.33 \%$ of patients and less than 1 minute ( 60 seconds) in $10 \%$ of patients. The average mean time and standard deviation of onset of 


\begin{tabular}{llllll}
\hline Table 1: Assessment ofHeart rate & & & & \\
\hline Time interval & Group I (n=25) & & Group II (n=25) & P-value \\
& Mean & SD & Mean & SD & \\
Baseline & 80.00 & 8.49 & 81.80 & 8.74 & 0.42 \\
\hline 5 minutes & 73.80 & 13.38 & 65.63 & 12.45 & 0.02 \\
15 minutes & 68.63 & 10.30 & 63.47 & 8.70 & 0.04 \\
30 minutes & 68.40 & 7.36 & 66.40 & 12.33 & 0.45 \\
45 minutes & 64.33 & 6.72 & 65.17 & 11.41 & 0.73 \\
60 minutes & 62.60 & 5.09 & 62.60 & 8.28 & 1.00 \\
75 minutes & 65.03 & 8.59 & 64.33 & 9.08 & 1.00 \\
90 minutes & 65.57 & 8.17 & 67.47 & 8.41 & 0.38 \\
105 minutes & 65.03 & 5.85 & 69.17 & 7.15 & 0.02 \\
120 minutes & 66.87 & 6.03 & 69.20 & 6.54 & 0.16 \\
135 minutes & 67.93 & 5.44 & 72.53 & 8.44 & 0.02 \\
150 minutes & 71.90 & 6.55 & 75.40 & 5.83 & 0.03 \\
165 minutes & 72.67 & 5.83 & 76.13 & 11.01 & 0.13 \\
180 minutes & 74.67 & 5.21 & 79.80 & 7.59 & 1.00 \\
\hline
\end{tabular}

\begin{tabular}{|llllll}
\hline Table 2: Assessment of mean arterial pressure & & & & \\
\hline Time interval & Group I (n=25) & Group II (n=25) & P-value \\
\hline & Mean & SD & Mean & SD & \\
\hline Baseline & 97.64 & 5.24 & 97.73 & 6.96 & 0.96 \\
\hline 5 minutes & 90.73 & 14.65 & 81.22 & 11.64 & 0.01 \\
\hline 15 minutes & 81.58 & 10.26 & 76.16 & 13.48 & 0.08 \\
\hline 30 minutes & 79.59 & 11.20 & 75.14 & 11.38 & 0.13 \\
\hline 45 minutes & 79.31 & 9.67 & 77.08 & 9.73 & 0.38 \\
\hline 60 minutes & 79.08 & 5.34 & 77.37 & 8.61 & 0.36 \\
\hline 75 minutes & 81.27 & 7.58 & 79.27 & 7.85 & 0.32 \\
\hline 90 minutes & 81.41 & 6.24 & 81.36 & 7.57 & 0.98 \\
\hline 105 minutes & 84.36 & 5.93 & 87.29 & 6.60 & 0.08 \\
\hline 120 minutes & 87.63 & 7.29 & 88.69 & 7.55 & 0.58 \\
\hline 135 minutes & 87.51 & 5.58 & 91.91 & 7.11 & 0.01 \\
\hline 150 minutes & 92.6 & 7.9 & 95.0 & 7.4 & 0.2 \\
\hline 165 minutes & 92.78 & 6.75 & 96.22 & 6.49 & 0.05 \\
\hline 180 minutes & 94.02 & 7.19 & 97.56 & 5.42 & 0.04 \\
\hline
\end{tabular}

sensory blockade in Group II are 129.6 102.4 seconds. Pvalue obtained is statistically significant.

[Figure 3] shows that the duration of onset of motor blockade (Time is taken to achieve Bromage 3) in $56.67 \%$ of patients in Group I is between 4 to 5 minutes, and between 3 to 4 minutes in $44.33 \%$ patients. The average mean time and standard deviation of onset of a motor blockade in Group I is $3.64 \pm 0.75$. The duration of onset of a motor blockade in $60 \%$ of patients in Group II is between 5 to 6 minutes, and between
4 to 5 minutes in $40 \%$ of patients. The average mean time and standard deviation of onset of a motor blockade in Group II are $4.57 \pm 0.83$ minutes. P-value obtained is statistically significant.

\section{Discussion}

Dexmedetomidine is a highly selective $\alpha_{2}$ adrenoceptor agonist with sedative and analgesic properties and has been 


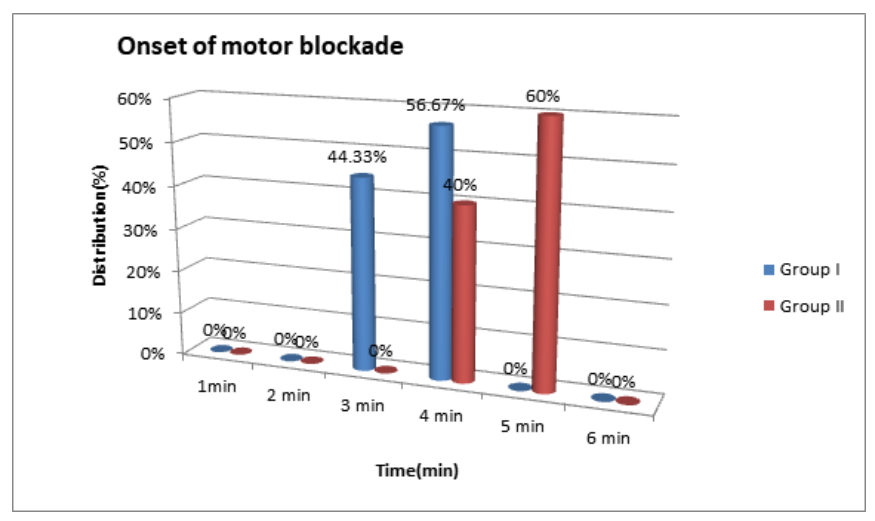

Figure 3: Time of Onset of Motor Block

approved by Food and Drug Administration (FDA) as a shortterm sedative for mechanically ventilated intensive care unit (ICU) patients. ${ }^{[8]} \mathrm{IV}$ dexmedetomidine has been found to reduce the anesthetic requirements during general anesthesia. It has been found to exert its analgesic actions both at the spinal and supraspinal levels. ${ }^{[9]}$ Dexmedetomidine is still under evaluation as an ideal neuraxial adjuvant as it provides stable hemodynamic conditions, good quality of intraoperative and prolonged postoperative analgesia with minimal side effects. Kanazi et al, ${ }^{[10]}$ demonstrated significant prolongation in the duration of sensory and motor block with dexmedetomidine used as an intrathecal additive for $0.5 \%$ heavy bupivacaine. The present study was conducted to assess the usefulness of $0.5 \%$ hyperbaric bupivacaine with dexmedetomidine on spinal anaesthesia in lower limb orthopaedic patients.

In the present study, the mean heart rate at baseline was 80.00 \pm 8.49 in group I and $81.80 \pm 8.74$ in group II. The mean heart rate at 5 minutes was $73.80 \pm 13.38$ in group I which was significantly higher $(\mathrm{p}=0.02)$ compared to $65.63 \pm 12.45$ in group II. The heart rate in both groups was found to be comparable at $30,45,60,75,90$ minutes $(\mathrm{p}>0.05)$.

Halder et al, ${ }^{[11]}$ in their study involved 80 patients, (20$60 \mathrm{yrs}$ ) posted for elective lower limb orthopedic surgery of traumatic origin under spinal anaesthesia were divided into 2 equal groups (Group $\mathrm{D}_{5} \& \mathrm{D}_{10}$ ) in a randomized, double-blind fashion. In this prospective parallel-group study, group $\mathrm{D}_{5}(\mathrm{n}=40) \quad 3 \mathrm{ml} \quad 0.5 \%$ hyperbaric bupivacaine $+5 \mu \mathrm{g}$ dexmedetomidine in $0.5 \mathrm{ml}$ of normal saline and group $\mathrm{D}_{10}(\mathrm{n}=40) 3 \mathrm{ml} 0.5 \%$ bupivacaine $+10 \mu \mathrm{g}$ dexmedetomidine in $0.5 \mathrm{ml}$ of normal saline were administered intrathecally. Sensory and motor block onset times and block durations, time to first analgesic use, total analgesic need, postoperative VAS, hemodynamics and side effects were recorded for each patient. Though with a similar demographic profile in both groups, sensory and motor block in group $\mathrm{D}_{10}(\mathrm{p}<0.05)$ was earlier than group $\mathrm{D}_{5}$. Sensory, motor block duration and time to first analgesic use were significantly longer and the need for rescue analgesics was lower in group $\mathrm{D}_{10}(\mathrm{p}<0.05)$ than $\mathrm{D}_{5} .24$ $\mathrm{h}$ VAS score was significantly lower in group $\mathrm{D}_{10}(\mathrm{p}<0.05)$. Intergroup hemodynamics was comparable $(\mathrm{p}>0.05)$ without any appreciable side effects.

We found that the mean arterial pressure at baseline was $97.64 \pm 5.24$ in group I and $97.73 \pm 6.96$ in group II suggesting MAP in both groups was comparable. The MAP at 5 minutes was $90.73 \pm 14.65$ in group I which was significantly higher $(p=0.01)$ compared to $81.22 \pm 11.64$ in group II, suggesting a greater fall from the baseline in group II compared to group I. The MAP in both groups was found to be comparable at 15 , $30,45,60,75,90,105,120$ minutes $(\mathrm{p}>0.05)$.

Rai et al, ${ }^{[12]}$ involved 30 patients each: Group D3 to receive $3 \mu \mathrm{g}$ of Inj. Dexmedetomidine $(0.5 \mathrm{ml}$, reconstituted using normal saline) along with $12.5 \mathrm{mg}(2.5 \mathrm{ml})$ of $0.5 \%$ hyperbaric bupivacaine and Group D5 to receive $5 \mu \mathrm{g}$ of Inj. Dexmedetomidine $(0.5 \mathrm{ml}$, reconstituted using normal saline) along with $12.5 \mathrm{mg}(2.5 \mathrm{ml})$ of $0.5 \%$ hyperbaric bupivacaine keeping the total volume of study drug constant in all 60 patients $(3 \mathrm{ml})$. Data recordings were done for time to reach the best sensory and motor block, intraoperative hemodynamic changes and time to first postoperative rescue analgesia. The two groups analysed were similar in terms of demographic profile, time to reach highest sensory block (T10) dermatome, time to reach Bromage scale 4, time to the surgical incision after spinal and the total duration of surgery $(p>0.05)$. The change in hemodynamics was similar $(\mathrm{p}>0.05)$. A statistically significant difference was observed in time to first rescue analgesia after skin closure with Group D3 having 206.47 minutes while in Group D5 the time was 271.33 minutes.

\section{Conclusion}

The authors found that dexmedetomidine was given intravenously as premedication before spinal anaesthesia using injection bupivacaine results in a quicker onset of analgesia, prolonged duration of sensory, motor block and well balanced hemodynamic parameters.

\section{References}

1. CM J, JA S. Actions of the hypnotic anaesthetic, dexmedetomidine, on noradrenaline release and cell firing in rat locus coeruleus slices. Br J Anaesth. 1993;71(3):447-449. Available from: https://doi.org/10.1093/bja/71.3.447.

2. Al-Ghanem SM, Massad IM, Al-Mustaf MM, Al-Zaben KR, Qudaisa IY, Qatawn AM, et al. Effect of Adding Dexmedetomidine versus Fentanyl to Intrathecal Bupivacaine on Spinal Block Characteristics in Gynecological Procedures: A Double Blind Controlled Study. Am J Appl. 2009;6(5):882887. Available from: https://doi.org/10.3844/ajassp.2009.882. 887. 
3. Al-Mustafa MM, Abu-Halaweh SA, Aloweidi AS, Murshidi MM, Ammari BA, Awwad ZM, et al. Effect of dexmedetomidine added to spinal bupivacaine for urological procedure. Saudi Med J. 2009;30(3):365-370.

4. Gupta R, Bogra J, Verma R, Kohli M, Kushwaha JK, Kumar S. Dexmedetomidine as an intrathecal adjuvant for postoperative analgesia. Indian J Anaesth. 2011;55(4):347-351. Available from: https://doi.org/10.4103/0019-5049.84841.

5. Zornow MH, Fleischer JE, Scheller MS, Nakakimura K, Drummond JC. Dexmedetomidine, an a2-adrenergic agonist decreases cerebral blood flow in the isoflurane anesthetized dog. Anesth Analg. 1990;70(6):624-650. Available from: https://doi.org/10.1213/00000539-199006000-00008.

6. Grewal A. Dexmedetomidine:New avenues. J Anaesthesiol Clin Pharmacol. 2011;27(3):297-302. Available from: https: //dx.doi.org/10.4103/0970-9185.83670.

7. $\mathrm{Yu}$ SB. Dexmedetomidine sedation in ICU. Korean $\mathrm{J}$ Anesthesiol. 2012;62(5):405-405. Available from: https://dx. doi.org/10.4097/kjae.2012.62.5.405.

8. Hayashi Y, Sumikawa K, Maze M, Yamatodani A, Kamibayashi T, Kuro M, et al. Dexmedetomidine Prevents Epinephrine-induced Arrhythmias Through Stimulation of Central $\alpha 2$ Adrenoceptors in Halothane-anesthetized Dogs. Anesthesiology. 1991;75(1):113-117. Available from: https://dx.doi.org/10.1097/00000542-199107000-00018.

9. Carollo DS, Nossaman BD, Ramadhyani U. Dexmedetomidine: a review of clinical applications. Curr Opin Anaesthesiol. 2008;21(4):457-461. Available from: https://dx.doi.org/ 10.1097/aco.0b013e328305e3ef.

10. Kanazi GE, Aouad MT, Jabbour-Khoury SI, Jazzar MDA, Alameddine MM, Al-Yaman R, et al. Effect of low- dose dexmedetomidine or clonidine on the characteristics of bupivacaine spinal block. Acta Anaesthesiol Scand. 2006;50(2):222-227. Available from: https://dx.doi.org/10. 1111/j.1399-6576.2006.00919.x.

11. Halder S, Das A. Effect of Different Doses of Dexmedetomidine as Adjuvant in Bupivacaine -Induced Subarachnoid Block for Traumatized Lower Limb Orthopaedic Surgery: A Prospective, Double-Blinded and Randomized Controlled Study. J Clin Diagn Res. 2014;8(11):1-06.

12. Rai A, Bhutia MP. Dexmedetomidine as an Additive to Spinal Anaesthesia in Orthopaedic Patients Undergoing Lower Limb Surgeries: A Randomized Clinical Trial Comparing Two Different Doses of Dexmedetomidine. J Clin Diagn Res . 2017;11(4):9-9. Available from: https://doi.org/10.7860/jcdr/ 2017/26241.9654.

Copyright: (C) the author(s), 2020. It is an open-access article distributed under the terms of the Creative Commons Attribution License (CC BY 4.0), which permits authors to retain ownership of the copyright for their content, and allow anyone to download, reuse, reprint, modify, distribute and/or copy the content as long as the original authors and source are cited.

How to cite this article: Arjun NR, Reddy G N, Prasad KN, Hegde UB. Usefulness of $0.5 \%$ Hyperbaric Bupivacaine with Dexmedetomidine on Spinal Anaesthesia in Lower Limb Orthopaedic Patients. Acad. Anesthesiol. Int. 2020;5(2):30-34.

DOI: dx.doi.org/10.21276/aan.2020.5.2.6

Source of Support: Nil, Conflict of Interest: None declared. 